\title{
From drug-oriented curriculum to patient- oriented curriculum in Chile: Alumni satisfaction as a quality indicator for a pharmacy programme
}

\author{
Guido Ruiz ${ }^{1}$ (D) Alejandra Ulloa², Monserratt Díaz², Alejandro Jerez Mora1 ${ }^{(\mathbb{D}}$ \\ 1 Institute of Pharmacy, Faculty of Sciences, Universidad Austral de Chile, Chile \\ ${ }^{2}$ School of Pharmacy, Faculty of Sciences, Universidad Austral de Chile, Chile
}

\section{Keywords}

Alumni satisfaction

Patient-oriented curriculum

Quality assurance

Correspondence
Guido Ruiz
Institute of Pharmacy
Faculty of Sciences
Universidad Austral de Chile
Independencia 631
Valdivia
Chile
guidoruiz@uach.cl

\begin{abstract}
Background: In 2005, a Health Care Reform in Chile established the role of pharmacists as contributors to achieving therapeutic goals. To fulfil the needs of the country in 2007 the pharmacy programme at Austral University of Chile started transiting from a drug-oriented to a patient-oriented curriculum. Objective: Monitoring this transition process using alumni satisfaction as a quality indicator. Methods: A questionnaire to assess alumni satisfaction with the pharmacy programme was designed and validated in its content and reliability. Subsequently, cross-sectional surveys over samples of graduates from both, drug-oriented and patient-oriented curriculum alumni were conducted. Satisfaction scores of both samples were statistically compared. Results: Cronbach's alpha for all six dimensions of the final questionnaire was $\geq 0.70$. The patient-oriented curriculum generated higher satisfaction scores $(p<0.001)$, noteworthy in dimensions 'Design and organisation', 'Teachers' and 'Emotional bonding with the program/university'. In three out of 34 items the patientoriented curriculum was less satisfactory than the drug-oriented one. Conclusions: Alumni satisfaction assessment is a useful source of feedback for quality assurance and continuous improvement of programmes. Considering this indicator, the transition of the pharmacy programme at Austral University of Chile to a patient-oriented curriculum was essentially successful.
\end{abstract}

\section{Introduction}

At the beginning of the $21^{\text {st }}$ century, pharmacy education in Chile was impacted by two great changes. First, the Health Care Reform effective from 2005 (Valdivieso \& Montero, 2010), that established a role for pharmacists as promoters of rational use of medicines and contributors to the achievement of therapeutic goals; Concepts such as 'pharmaceutical services' and 'pharmaceutical care' were formally introduced in the Chilean law (Res. 515 Aprueba Política Nacional de Medicamentos en la Reforma de Salud, 2004). Second, the establishment of the Chilean Quality Assurance System in 2006 (Ley 20.129 Establece Un Sistema Nacional de Aseguramiento de la Calidad de la Educación Superior, 2006). The system introduced policies to promote, among other aspects, quality and pertinence of institutions of higher education in Chile, creating an appropriate environment for continuous quality assessment (Acuña-Johnson, 2018). As a consequence, many pharmacy programmes transited from a drug-oriented to a patient-oriented curriculum, that being the case of the pharmacy programme at Austral University of Chile (UACh). This programme started in 1994, largely based on chemical and biomedical sciences, whereas healthoriented term courses were compressed the fifth year. That curriculum was taught for 12 years before being replaced in 2007 by a second, patient-oriented one. In the patient-oriented curriculum, the cycle of basic sciences was shortened from 2.5 to 1.5 years; the cycle of professional courses was extended from one to two years; 
clinical pharmacy was covered by four courses, two on therapeutics, one in 'clinical pharmacology and pharmaceutical care' and a 'clinical and hospital experience' course. A course on English language intended for pharmacy practice was also incorporated. Additionally, in the patient-oriented curriculum the experiential rotations started earlier, and its number increased from two to three. The final internship was diversified towards hospital pharmacy, clinical pharmacy, and primary care; This second curriculum was subsequently modified in 2018, with minor adjustments (Universidad Austral de Chile, n.d.).

The change of pharmacy curriculum at UACh was understood as an adaptative process to reflect the contemporary pharmacy practice, embracing new roles of pharmacists in hospital and clinical pharmacy (AcuñaJohnson, 2018). This programme was accredited in 2016 by the National Accreditation Commission, the Chilean governmental institution which validates accreditation of institutions and programmes in higher education (Cancino \& Schmal, 2014). Accreditation of pharmacy programmes is a voluntary process in Chile, and its execution converges in part with international recommendations, such as those proposed in FIP's Quality Assurance Framework (FIP, 2014). Nonetheless, Outcomes and Impact are domains of quality poorly evaluated in the Chilean process, since explicit references to evaluation criteria are infrequent and references to external indicators are practically inexistent (Zapata \& Clasing, 2016).

FIP's Framework establishes that the most visible outcomes of an educational programme are the graduates, 'who should be competent and capable of performing safely, effectively and professionally in their practice setting and contributing to the delivery of health care' (FIP, 2014). Among the approaches that have been proposed to evaluate the quality of a curriculum, the satisfaction of alumni (understood as graduates from a specific programme) with the educational programme is considered an authorised source of information to assess whether the knowledge and skills developed in the programme can relate to what is required in the workplace (Harvey \& Langley, 1995; Hsu et al., 2016; Jennings, 1989). In health careers and particularly in pharmacy, items related to satisfaction of alumni with programmes have been part of job satisfaction surveys (Gustafsson et al., 2018; Jalal et al., 2018; Joyner et al., 2009). Recently, Gustafsson and authors published the results of a brief survey on education satisfaction among pharmacy graduates in Sweden (Gustafsson et al., 2021). However, as far as we know, validated instruments addressed specifically to assess alumni satisfaction with the pharmacy programme are absent in the literature.
The present study was aimed to monitoring the transition of the pharmacy programme at UACh from a drugoriented curriculum to a patient-oriented curriculum, using alumni satisfaction as an outcome-based quality indicator. For that purpose, a questionnaire to evaluate alumni satisfaction was designed, validated and administered as a cross-sectional survey to samples of alumni of both curriculums. Then, satisfaction scores of those two samples were compared. The findings will be useful as feedback for quality assurance and continuous improvement of the programme, reflecting contemporary pharmacy practice and the needs of the country.

\section{Methods}

\section{Questionnaire design and validation}

A preliminary questionnaire was created using a five-step Likert-type scale, from 'strongly disagree' to 'strongly agree', over declarative sentences (items). Items were adapted specifically for pharmacists from a survey used at University Austral de Chile to assess the satisfaction of students. Items intended specifically to students and those not suitable for graduates were eliminated. The sentences were in Chilean Spanish and the wording of each item was carefully reviewed with special attention to the consistency in the editing. To establish that individual items are relevant to the construct and that all key items or indicators were considered, a preliminary questionnaire was submitted to a panel of 12 experts, peer-recognised pharmacists from different practice areas (community pharmacy, hospital pharmacy, primary care, pharmaceutical industry, and academy) with ten or more years of regular professional practice. A content validation form was created, defining the construct and asking experts to evaluate the relevance of each item regarding the construct, by means of an item level content validity index (I-CVI) using a five-step Likert-type scale. For a given expert, an item was considered valid when it was rated 3 or more. Only items considered valid by all the experts (100\% of agreement) were considered content valid and finally included in the questionnaire. Experts were also encouraged to incorporate sentences about specific aspects and to provide open feedback on the wording and drafting, to improve intelligibility (i.e. face validity). When three or more experts were spontaneously in accordance about a remark, that remark was accepted. After content validation, a group of 20 professionals completed the survey. The data collected were processed to evaluate the reliability of the questionnaire. The internal consistency of a priori dimensions of the questionnaire was measured by 
the Cronbach's alpha coefficient. With an alpha $>0.70$, consistency was considered as satisfactory.

\section{Survey administration}

To assess alumni satisfaction, a cross-sectional survey over samples of both, drug-oriented curriculum graduates and patient-oriented curriculum graduates was conducted. The first sample frame comprised alumni graduated between January $1^{\text {st }}$ of 2003 and December 31 $31^{\text {st }}$ of 2007 (drugoriented curriculum, 145 professionals) and the second one, alumni graduated between January $1^{\text {st }}$ of 2012 and December 31 $1^{\text {st }}$ of 2016 (patient-oriented curriculum, 155 professionals). The questionnaire was conducted as an inperson survey in two different times, 2011 (drug-oriented curriculum) and 2018 (patient-oriented curriculum). The list of graduates was obtained from the university's database and the contact information was obtained from the database or by means of social networking. Alumni were initially contacted either by phone or by e-mail by the survey taker. They were asked to fulfil the interview as an in-person interview or, conversely, as phone interview. Sending an e-mail with the questionnaire was considered only when a graduate declined to answer an interview. Consent was assumed upon interview acceptance and negatives to fulfil the survey were immediately accepted. Not having successful contact after three attempts was also interpreted as negative to fulfil the survey. Questionnaire items were randomly ordered in the survey. Besides the questionnaire, alumni were requested to provide information on professional practice and demographics, including sex, age and practice area. Data was anonymised by replacing names with random numbers and remained confidential.

\section{Ethical considerations}

Not being a biomedical in its nature, no ethical committee approval was sought prior to beginning this research because it is not mandatory under Chilean law. Nonetheless, all respondents were provided information about the aim of the study and were advised that data would be treated as strictly confidential.

\section{Data analysis}

Continuous data (total scores) were expressed as mean \pm standard deviation (SD). Individual total scores were normalised as percentages of the maximum score (i.e. all items scoring 5) of a given dimension. Normalisation process weights equally the dimensions and allows comparisons among dimensions with disparate number of items. Discrete data were averaged and expressed as media and interquartile range (IQR $\left.Q_{3}-Q_{1}\right)$. Categorical data was expressed as percentages. Parametric tests (One or Two-way MANOVA, repeated measures ANOVA, Twoway ANOVA) and non-parametric tests (Mann-Whitney $U$ test, Fischer's exact test) were used as appropriate. A $p$ value $<0.05$ indicated statistical significance. All analyses were conducted using the Statistical Package for the Social Sciences (SPSS) for Windows version 23.0.

\section{Results \\ Questionnaire validation}

From a preliminary version of the questionnaire, experts excluded two items. There was experts' agreement about incorporating four new items, regarding programme facilities, equipment for laboratory work and number of experiential rotations. Minor changes on wording were also made. The questionnaire that entered the reliability test included 34 items, distributed in six a priori dimensions: D1 Design and organisation; D2 Contents and fulfillment; D3 Physical Resources; D4 Teachers; D5 Professional focus; D6 Emotional bonding with the programme/university (Table I). Table I summarises the results of the reliability test for the six dimensions. For each dimension, the Cronbach's alpha was $\geq 0.70$, ranging from 0.73 (D3 Physical Resources) to 0.93 (D1 Design and organisation).

\section{Descriptive data}

Within alumni from the drug-oriented curriculum, 114 completed the survey (78.6\% response rate). Most of the surveys were conducted as in-person interviews (66.7\%). From this sample, 81 (71.1\%) of respondents were women (76.4\% response rate) and 33 (28.9\%) were men $(84.6 \%$ response rate). The distribution according to Professional Practice Area was $59.6 \%$ for 'Community Pharmacy', 28.9\% for 'Hospital Pharmacy/Primary Care' and $10.5 \%$ for 'Other Areas' (Pharmaceutical Industry, Regulatory Affairs and Academia). Within alumni from the patient-oriented curriculum, 82 completed the survey $(52.9 \%$ response rate). The survey was also conducted mainly as an inperson interview (62.9\%). From this sample, 54 (65.8\%) were women (56.2\% response rate) and 28 (34.2\%) were men (47.5\% response rate). The distribution of the sample by Professional Practice Area was $52.4 \%$ in 'Community Pharmacy', $37.8 \%$ in 'Hospital Pharmacy/Primary Care' and $9.8 \%$ in 'Other'. There were no missing values. 
Table I: Reliability of the questionnaire 'Alumni Satisfaction with the Pharmacy Programme'.

\begin{tabular}{|c|c|}
\hline Dimension and Cronbach's alpha value & Item \\
\hline $\begin{array}{l}\text { D1: } \\
\text { Design and organisation } \\
\alpha=0.88\end{array}$ & $\begin{array}{l}\text { 1.Regarding the disciplinary relation among courses, the programme was consistent } \\
\text { 2.The quantity of elective courses was appropriate } \\
\text { 3.The quality of elective courses was optimal } \\
\text { 4.Along the programme, theoretical learning was appropriate } \\
\text { 5.Along the programme, practical learning was appropriate } \\
\text { 6.The curriculum structure allowed a good under-graduate training }\end{array}$ \\
\hline $\begin{array}{l}\text { D2: } \\
\text { Contents and fulfillment } \\
\alpha=0.85\end{array}$ & $\begin{array}{l}\text { 1.The academic standard of the programme was appropriate } \\
\text { 2.Along the programme, the study objectives were clearly perceived } \\
\text { 3.Along the programme, the practical courses were evidently useful } \\
\text { 4.The skills developed for carrying out computing activities were those necessary } \\
\text { 5.Along the programme, essential skills about English language were developed } \\
\text { 6.Along the programme, learning on ethics was appropriate }\end{array}$ \\
\hline $\begin{array}{l}\text { D3: } \\
\text { Physical resources } \\
\alpha=0.73\end{array}$ & $\begin{array}{l}\text { 1.The facilities to conduct academic activities were optimal and sufficient } \\
\text { 2.The equipment for practical work was sufficient and updated } \\
\text { 3.Library resources allowed an optimal training, being sufficient and updated } \\
\text { 4.There was opportune availability of library resources }\end{array}$ \\
\hline $\begin{array}{l}\text { D4: } \\
\text { Teachers }\end{array}$ & $\begin{array}{l}\text { 1.The number of teachers in the professional cycle was appropriate } \\
\text { 2.There was enough trainers' support to carry out internships or theses } \\
\text { 3.There was enough trainers' support to carry out professional rotations } \\
\text { 4.Teachers reached a high academic standard }\end{array}$ \\
\hline$\alpha=0.80$ & 5.The number of teachers in basic science was appropriate \\
\hline $\begin{array}{l}\text { D5: } \\
\text { Professional focus } \\
\alpha=0.93\end{array}$ & $\begin{array}{l}\text { 1.The training on teamwork skills was appropriate } \\
\text { 2.The elective courses offered were useful for professional training } \\
\text { 3.The knowledge developed during the programme is highly relevant in professional working areas } \\
\text { 4.There was extensive field knowledge about different professional working areas } \\
\text { 5.The hospital rotation as it was conducted, was essential for my professional training } \\
\text { 6.The number of internships related to a professional role was enough } \\
\text { 7.The quality of experiential rotations was appropriate } \\
\text { 8.Along the programme, it was possible to establish links with other professionals }\end{array}$ \\
\hline $\begin{array}{l}\text { D6: } \\
\text { Emotional bonding with the } \\
\text { programme/university } \\
\alpha=0.85\end{array}$ & $\begin{array}{l}\text { 1.There is a recognisable professional profile for pharmacists graduated at UACh } \\
\text { 2.If I could go back in time, I would study Pharmacy at UACh again } \\
\text { 3.I recommend other people to study pharmacy at UACh } \\
\text { 4.I feel identified with the School of Pharmacy at UACh } \\
\text { 5. When I meet other pharmacists, I proudly state that I studied at UACh }\end{array}$ \\
\hline
\end{tabular}

Cronbach's alpha value for each dimension of the questionnaire over the answers of 20 professionals. The original questionnaire was developed in Chilean Spanish. This translation has not been validated and is merely illustrative.

\section{Analysis of satisfaction scores}

Total scores from both samples passed the normality test (D’Agostino and Pearson) and parametric tests were subsequently applied. Considering normalised total scores of the six dimensions of the questionnaire 'Alumni satisfaction with the pharmacy programme', the difference between both samples was extremely significant (One-way MANOVA, Wilks' Lambda $=0.802, p<$ 0.001 ). In the sample of the drug-oriented curriculum, dimensions scored totals between $64.4 \%$ and $74.4 \%$, being D6 Emotional bonding with the program/university the highest scored dimension, with $74.4 \% \pm 14.2$ (mean \pm $\mathrm{SD})$. Compared with those of the same sample, the lower total scores were in D1 Design and organisation $(64.4 \% \pm$ $12.0)$ and D5 Professional focus $(64.5 \% \pm 11.0)(p<0.001$, repeated measures ANOVA, Tukey post-test) (Figure 1A). In the sample of the patient-oriented curriculum, dimensions scored between $67.7 \%$ and $83.1 \%$. D4 Teachers and D6 Emotional bonding with the programme/ university were highly scored, with $79.8 \% \pm 12.3$ and $83.1 \% \pm 12.3$ respectively, compared with the other dimensions of that same sample $(p<0.001$, repeated measures ANOVA, Tukey post-test) (Figure 1B).

Comparing both samples, significantly higher total scores among respondents from the patient-oriented curriculum were found in D1 Design and organisation, D4 Teachers and D6 Emotional bonding with the programme/ university, compared with the counterparts from the drugoriented curriculum (Two-Way ANOVA, Bonferroni posttest, $p<0.001$ ) (Figure 2). No differences in scores for D2 
A

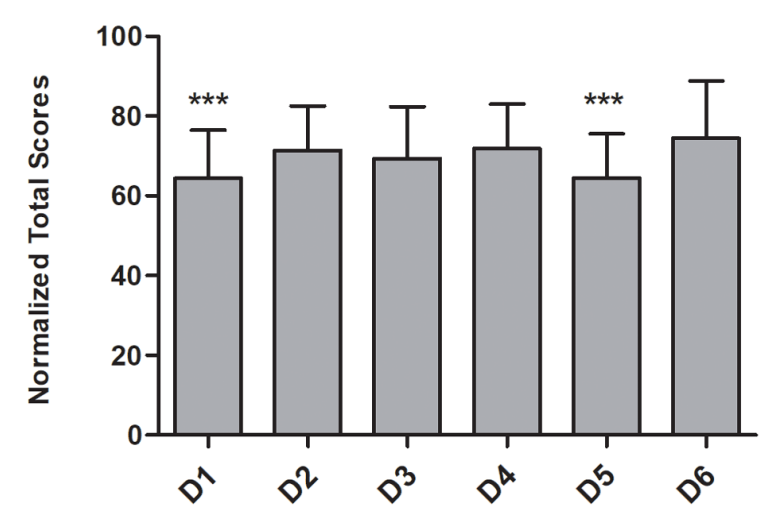

Dimensions of the Construct
B

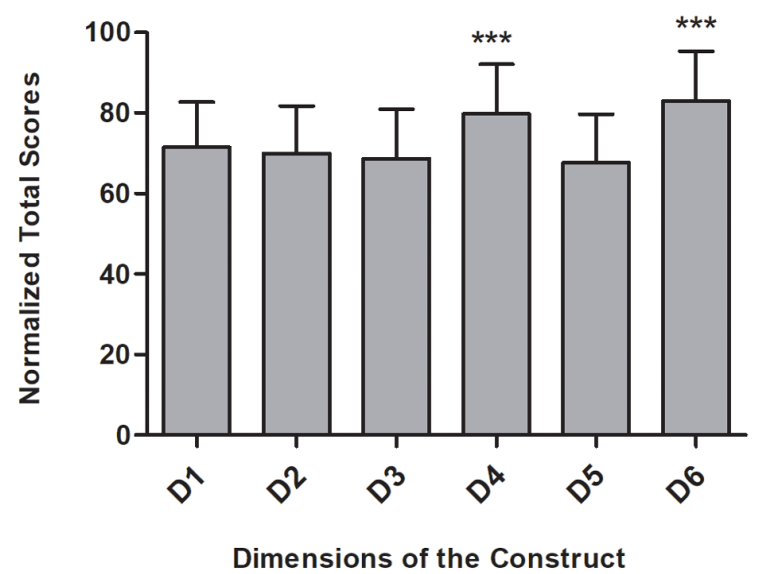

Columns represent normalised total scores per dimension from the samples of (A) drug-oriented curriculum and (B) patient-oriented curriculum. Dimension code: D1 = Design and organisation; D2 = Contents and fulfilment; D3 = Physical Resources; D4 = Teachers; D5 = Professional focus; D6 = Emotional bonding with the programme/university. Asterisks indicate significant differences within the sample.

$* * * p<0.001$, repeated measures ANOVA, Tukey post-test, mean \pm SD

Figure 1: Scores of alumni satisfaction with the pharmacy programme

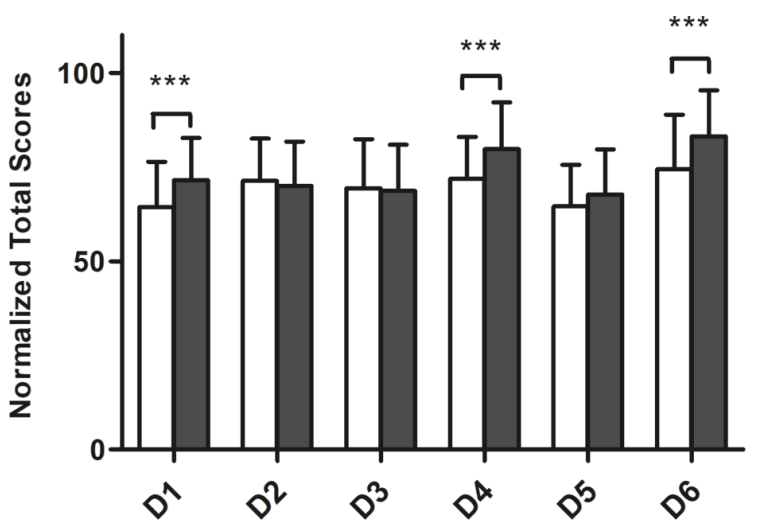

Dimensions of the Construct

Columns represent normalised total scores per dimension for the samples of drug-oriented curriculum (open columns) and patientoriented curriculum (solid columns). Dimension code: D1 = Design and organisation; D2 = Contents and fulfilment; D3 = Physical Resources; D4 = Teachers; D5 = Professional focus; D6 = Emotional bonding with the programme/university. Asterisks indicate significant differences comparing matched dimensions of both samples.

$* * * p<0.001$, Two-Way ANOVA, Bonferroni post-test, mean \pm SD.

Figure 2: Comparison of scores of alumni satisfaction with the pharmacy programme
Contents and fulfillment, D3 Physical Resources and D5 Professional focus were found between the samples. Moreover, the effect of the Area of Professional Practice over satisfaction was evaluated. There were no significant differences on normalised total scores associated to this variable (Two-way MANOVA, Wilks Lambda $=0.927, p=$ 0.286).

For a better understanding of the response behaviour of graduates, averaged item scores of the Likert-type scale per dimension were compared. Table II summarises the computed median and IQR for those values. Among alumni from the drug-oriented curriculum, the lower item scores were in D1 Design and organisation, D3 Physical Resources and D5 Professional focus. The median of averaged item scores in the three other dimensions was 4 (IQR 4-3). Among alumni from the patient-oriented curriculum, the lower item scores were also in D3 Physical Resources and D5 Professional focus. As in the continuous data analysis, we found significantly higher scores among respondents from the patient-oriented curriculum in D1 Design and organisation ( $p<0.001)$, D4 Teachers $(p<$ 0.01) and D6 Emotional bonding with the programme/ university $(p<0.001)$ (Mann-Whitney $\mathrm{U}$ test). 
Table II: Median and interquartile range $\left(Q_{3}-Q_{1}\right)$ of scores from the questionnaire 'Alumni satisfaction with the pharmacy programme' per dimension

\begin{tabular}{llll}
\hline Dimension & \multicolumn{2}{l}{$\begin{array}{l}\text { Drug-oriented } \\
\text { curriculum } \\
\text { Median }\left(\mathbf{Q}_{3}-\mathbf{Q}_{1}\right)\end{array}$} & $\begin{array}{l}\text { Patient-oriented } \\
\text { curriculum } \\
\text { Median }\left(\mathbf{Q}_{3}-\mathbf{Q}_{1}\right)\end{array}$ \\
D1. Design and organisation & $3(4-2.5)$ & $4(4-3.5)$ & $* *$ \\
D2. Contents and fulfillment & $4(4-3)$ & $4(4-3)$ & n.s. \\
D3. Physical resources & $3.5(4-3)$ & $3.5(4-3)$ & n.s. \\
D4. Teachers & $4(4-3)$ & $4(5-4)$ & $*$ \\
D5. Professional focus & $3(4-2.5)$ & $3.5(4-3)$ & n.s. \\
D6. Emotional bonding with & $4(4-3)$ & $4(5-4)$ & $* *$
\end{tabular}

the programme/university

Samples of alumni from a drug-oriented curriculum and a patient-oriented curriculum were compared. Asterisks indicate a significant difference using the Mann-Whitney U test. n.s. non-significant, ${ }^{*} p<0.01,{ }^{* *} p<0.001$,

The percentage of alumni reporting dissatisfaction with the pharmacy programme (i.e. median $\leq 3$ ) was also studied. Table III summarises those results. Comparing dimension by dimension, the percentage of dissatisfied respondents was lower among those from the patient-oriented curriculum, except in D2 Contents and fulfillment where the dissatisfied respondents of the drug-oriented sample were $22.8 \%$ while in the patient-oriented sample were 26.8\%. Noticeably, in D1 Design and organisation the percentage of dissatisfied alumni diminished from $48.2 \%$ to $24.4 \%$ with change of curriculum ( $p<0.001$ ), whereas in D6 Emotional bonding with the programme/university, it diminished from $26.3 \%$ to $13.4 \%(p<0.05)$ (Fischer's exact test).

\section{Item exploration}

Considering that D2 Contents and fulfillment, D3 Physical Resources and D5 Professional focus are dimensions that remained low scored in both samples, those dimensions were explored to find items that consistently received

Table III: Percentages of respondents with median of scores $\leq \mathbf{3}$ from the questionnaire 'Alumni satisfaction with the pharmacy programme' per dimension

\begin{tabular}{|c|c|c|}
\hline Dimension & $\begin{array}{l}\text { Drug-oriented } \\
\text { curriculum }\end{array}$ & $\begin{array}{l}\text { Patient-oriented } \\
\text { curriculum }\end{array}$ \\
\hline D1. Design and organisation & $48.2 \%$ & $24.4 \% * *$ \\
\hline D2. Contents and fulfillment & $22.8 \%$ & $26.8 \%$ \\
\hline D3. Physical Resources & $36.0 \%$ & $34.1 \%$ \\
\hline D4. Teachers & $25.4 \%$ & $17.1 \%$ \\
\hline D5. Professional focus & $47.4 \%$ & $40.2 \%$ \\
\hline $\begin{array}{l}\text { D6.Emotional bonding with the } \\
\text { programme/university }\end{array}$ & $26.3 \%$ & $13.4 \% *$ \\
\hline
\end{tabular}

Samples of alumni from a drug-oriented curriculum and a patient-oriented curriculum were compared. Asterisks indicate a significant difference using Fischer's exact test. ${ }^{*} p<0.05, * * p<0.001$ dissatisfactory scores. Table IV summarises those results. The median of scores showed dissatisfactory answers in respondents from the patient-oriented curriculum than in respondents from the drug-oriented one in three items. Those items were related to skills to carrying out computing activities, skills in English language (both from D2 Contents and fulfillment) and to facilities to conduct academic activities (from D3 Physical Resources). This last item had a very low score in the patient-oriented curriculum, with a median of 2.5 (IQR 4-2).

Finally, since D4 and D6 were the highest-scored dimensions in the sample of the patient-oriented curriculum, we explored those dimensions to find items expressing the highest levels of satisfaction. Both items were from D6 Emotional bonding with the programme/ university'.

Table IV: Median and interquartile range $\left(Q_{3}-Q_{1}\right)$ of scores of items from the questionnaire 'Alumni satisfaction with the pharmacy programme'

\begin{tabular}{|c|c|c|c|}
\hline Dimension & Item & $\begin{array}{l}\text { Drug-oriented } \\
\text { curriculum } \\
\text { Median ( } \mathbf{Q}_{3-} \\
\left.\mathbf{Q}_{1}\right)\end{array}$ & $\begin{array}{l}\text { Patient-oriented } \\
\text { curriculum } \\
\text { Median }\left(\mathbf{Q}_{3}-\mathbf{Q}_{1}\right)\end{array}$ \\
\hline \multirow[t]{2}{*}{ D2 } & $\begin{array}{l}\text { - The skills developed to } \\
\text { carrying out computing } \\
\text { activities were those } \\
\text { necessary }\end{array}$ & $3(4-2)$ & $3(3-2)$ \\
\hline & $\begin{array}{l}\text {-Along the programme, } \\
\text { essential skills about } \\
\text { English language were } \\
\text { developed }\end{array}$ & $3(4-2)$ & $3(3-2)$ \\
\hline \multirow[t]{2}{*}{ D3 } & $\begin{array}{l}\text {-The facilities to con- } \\
\text { duct academic activities } \\
\text { were optimal and suf- } \\
\text { ficient }\end{array}$ & $4(4-2)$ & $2.5(4-2)$ \\
\hline & $\begin{array}{l}\text {-The equipment for } \\
\text { practical work was suf- } \\
\text { ficient and updated }\end{array}$ & $3(4-2)$ & $3(4-2)$ \\
\hline \multirow[t]{2}{*}{ D5 } & $\begin{array}{l}\text {-There was extensive } \\
\text { field knowledge about } \\
\text { different professional } \\
\text { working areas }\end{array}$ & $3(4-2)$ & $3(4-2)$ \\
\hline & $\begin{array}{l}\text {-The number of ex- } \\
\text { periential rotations was } \\
\text { enough }\end{array}$ & $3(4-2)$ & $3.5(4-2)$ \\
\hline \multicolumn{4}{|c|}{$\begin{array}{l}\text { Items with the lower scores among alumni of both curriculums are } \\
\text { shown. }\end{array}$} \\
\hline
\end{tabular}

In the present study the transition of the pharmacy programme at UACh from a drug-oriented to a patientoriented curriculum was monitored, using alumni satisfaction as an outcome-based quality indicator. The validation of the questionnaire demonstrated that it is a 
reliable instrument to assess alumni satisfaction with the pharmacy programme in Chile. The data analysis showed that the patient-oriented curriculum is related to significantly higher satisfaction scores when compared with the drug-oriented one.

Adaptation of an existent questionnaire has been regarded as an efficient procedure, and more practical than starting from scratch if the resulting questionnaire is then properly validated (Artino et al., 2014). This method also provides a framework for comparisons with data from current students and allows assessments of criteria considered important by the university. In the validation process we found a high level of internal consistency for each dimension of the questionnaire Alumni Satisfaction with the Pharmacy Programme. It is understandable that D3 Physical Resources, with only four items, had the lower Cronbach's alpha value, since alpha is affected by the number of items (Cortina, 1993).

The improvement in satisfaction scores for D1 Design and organisation, can be interpreted as the result of the increase in the number and proportion professional courses. The improvement of D4 Teachers is directly related to the enrichment of professional area since it was necessary to hire five new professors and three new instructors to implement the patient-oriented curriculum. The interpretation of the high score for D6 Emotional bonding with the programme/university in the patientoriented sample is more complex, since several factors concur in the emotional attachment of alumni with their programme and alma mater. University experience is shaped by both, academic and social systems (Gaier, 2005), being the curriculum just a part of the academic system. This statement is valid to this study's results, since these cannot be exclusively associated to the changes in the curriculum, but also to social and academic improvements at UACh. As it was previously stated, a major objective of the curricular change was to broaden the professional focus of the programme towards hospital and clinical pharmacy. Therefore, a significant improvement in satisfaction scores of D5 Professional Focus was expected, that not being the case. A simple interpretation is that professional practice in Chile is demanding knowledge and skills that are not yet adequately covered by the patient-oriented curriculum, but further research is needed to confirm this statement and to apply corrective measures.

Regarding the dimensions where the satisfaction scores did not improve in the patient-oriented sample, the item exploration confirmed that it was due to some specific, critical items, being this finding an important feedback to improve the current curriculum. In the case of D2 Contents and fulfillment, critical items where those related with computing skills and English language. The dissatisfaction about computing skills can be related to a deficient training on software commonly used at practice settings. This weakness of the patient-oriented curriculum deserves special attention since pharmacy students must be educated in pharmacy informatics to be able to leverage existing and future tools to support medication-related care (Fox et al., 2011). About the English language, a specific course for pharmacist was integrated to the patient-oriented curriculum, being the last of three courses on English language along the programme. English is the language of the science, and this is especially true for pharmaceutical sciences, where less than $1.2 \%$ of bibliographic references contained in international pharmaceutical journals are published in languages other than English (Edouard, 2009). The present results indicate that it is still necessary to reinforce or to redirect the training in this important area. Regarding D3 Physical Resources, the item about number and quality of facilities was a critical one in the patient-oriented curriculum. Although undesired, this was an expected result. In 2007 a fire destroyed the Science Faculty main building, including the pharmacy programme facilities. The gradual process of recovery of definitive installations finished in 2020 . The impact of the new facilities on student and alumni satisfaction should be evaluated by future studies.

Among several factors such as job satisfaction, job success and professional income, work experience, perceived quality of the university, it was demonstrated that the perceived quality of the programme is the most relevant factor shaping the satisfaction of alumni (Hartman \& Schmidt, 1995; Hsu et al., 2016; Pace, 1979; Espinoza et al., 2019). Reviewers and early researchers in the areas of job, life, self, and patient satisfaction agree that satisfaction is a function of an initial standard and some perceived discrepancy from the initial reference point (Oliver, 1980). Consequently, alumni satisfaction can be considered as a measure of the expected performance of an undergraduate programme contrasted with the perceived real performance of that programme once the knowledge and skills are required. Based on these concepts, we agree with the postulate that alumni satisfaction represent a reliable, outcome-based indicator of the quality of a programme (Harvey \& Langley, 1995; Jennings, 1989), these being the indicators necessary for quality assurance of pharmacy education (FIP, 2014). Interestingly, a study evaluating education satisfaction in two cohorts of pharmacy graduates in Sweden was recently published (Gustafsson et al., 2021); The authors used a ten-question survey, and the Likert-type scales data was dichotomised in the statistical analysis. As the 
external validity of this type of study, however, is limited to a local context, comparisons are difficult and not effective. Yet, despite all the differences, both studies share the same framework and rationale, establishing that satisfaction among pharmacy graduates may help educators to further develop the programmes.

This study has some limitations. Since the six dimensions cover different aspects of the undergraduate experience related to a pharmacy programme, they were assumed as orthogonal and statistically independent, and exploratory factor analyses were obviated. This also was the basis for scoring each dimension separately. Although the results support this assumption, only a test of discriminant validity can confirm it. Another limitation of this study relies in the sampling process and the overall response rate. A response rate greater than approximately $60 \%$ was traditionally used as a marker to suggest a relatively low probability of nonresponse bias because it was assumed that there would be adequate representation of different respondent characteristics with so many people responding (Phillips et al., 2016). In the present study nonresponse bias cannot be discarded. Otherwise, all the computed results were quite consistent and had little dispersion. Although it does not account for the validity of convenience samples, it means that measures had comparable precision.

\section{Conclusion}

Alumni satisfaction with the pharmacy programme assessed using a validated questionnaire represents a useful, reliable source of feedback and an indicator of programme quality. In the present study the satisfaction of alumni from the patient-oriented curriculum was significantly higher than that of alumni from the drugoriented one. Therefore, the transition of pharmacy programme at UACh to patient-oriented curriculum was considered essentially successful. Specific and important weaknesses of the patient-oriented curriculum were also detected. Consequently, these findings will be useful for future and continuous improvements of the programme, addressing quality assurance.

\section{Funding}

This work was partially supported by the School of Pharmacy at Austral University of Chile.

\section{Conflict of interests}

The authors declare no conflict of interests.

\section{References}

Acuña-Johnson, P. (2018). Regulatory and Legal Issues in Pharmacy Education: Cases in Latin American Countries. In A. I. Fathelrahman, M. I. Mohamed Ibrahim, A. A. Alrasheedy, \& A. I. Wertheimer (Eds.), Pharmacy Education in the Twenty First Century and Beyond (1st ed., pp. 271-284). Academic Press. https://doi.org/10.1016/b978-0-12-811909-9.00016-2

Artino, A.R., La Rochelle, J.S., Dezee, K.J., \& Gehlbach, H. (2014). Developing questionnaires for educational research: AMEE Guide No. 87. Medical Teacher, 36(6), 463-474. https://doi.org/10.3109/0142159X.2014.889814

Cancino C.V., \& Schmal S.R. (2014). Sistema de Acreditación Universitaria en Chile: ¿Cuánto hemos avanzado? [University Accreditation System in Chile: What have we Come?]. Estudios Pedagógicos (Valdivia), 40(1), 4160. https://doi.org/10.4067/s0718-07052014000100003

Cortina, J. M. (1993). What Is Coefficient Alpha? An Examination of Theory and Applications. Journal of Applied Psychology, 78(1), 98-104. https://doi.org/10.1037/0021-9010.78.1.98

Edouard, B. (2009). Who Cites Non-English-Language Pharmaceutical Articles? Annals of Pharmacotherapy, 43(3), 549-550. https://doi.org/ 10.1345/aph.1L490

Espinoza, O., González, L.E., McGinn, N., Castillo, D., \& Sandoval, L. (2019). Factors that affect post-graduation satisfaction of Chilean university students. Studies in Higher Education, 44(6), 1023-1038. https://doi.org/10.1080/03075079.2017.1407306

FIP (International Pharmaceutical Federation). (2014). Quality Assurance of Pharmacy Education : the FIP Global Framework (International Pharmaceutical Federation (ed.))

Fox, B.I., Flynn, A.J., Fortier, C.R., \& Clauson, K.A. (2011). Knowledge, skills, and resources for pharmacy informatics education. American Journal of Pharmaceutical Education, 75(5). https://doi.org/10.5688/ ajpe75593

Gaier, S. (2005). Alumni Satisfaction with Their Undergraduate Academic Experience and the Impact on Alumni Giving and Participation. International Journal of Educational Advancement, 5(4), 279-288. https://doi.org/10.1057/palgrave.ijea.2140220

Gustafsson, M., Mattsson, S., Wallman, A., \& Gallego, G. (2018). Pharmacists' satisfaction with their work: Analysis of an alumni survey. Research in Social and Administrative Pharmacy, 14(7), 700-704. https:// doi.org/10.1016/j.sapharm.2017.08.006

Gustafsson, M., Wallman, A., \& Mattsson, S. (2021). Education Satisfaction among Pharmacy Graduates in Sweden. Pharmacy, 9(1), 44. https://doi.org/10.3390/pharmacy9010044

Hartman, D.E., \& Schmidt, S.L. (1995). Understanding student/alumni satisfaction from a consumer's perspective: The effects of institutional performance and program outcomes. Research in Higher Education, 36(2), 197-217. https://doi.org/10.1007/BF02207788

Harvey, J., \& Langley, A. (1995). Applying Quality Principles in Business Schools: Potential and Limitations. Canadian Journal of Administrative 
Sciences / Revue Canadienne Des Sciences de l'Administration, 12(2), 128-143. https://doi.org/10.1111/j.1936-4490.1995.tb00652.x

Hsu, S.H., Wang, Y.C., Cheng, C.J., \& Chen, Y.F. (2016). Developing a decomposed alumni satisfaction model for higher education institutions. Total Quality Management and Business Excellence, 27(9-10), 979-996. https://doi.org/10.1080/14783363.2015.1054102

Jalal, Z., Cox, A., Goel, N., Vaitha, N., King, K., \& Ward, J. (2018). Communications Skills in the Pharmacy Profession: A Cross Sectional Survey of UK Registered Pharmacists and Pharmacy Educators. Pharmacy, 6(4), 132. https://doi.org/10.3390/pharmacy6040132

Jennings, E.T. (1989). Accountability, Program Quality, Outcome Assessment, and Graduate Education for Public Affairs and Administration. Public Administration Review, 49(5), 438. https://doi.org/ $10.2307 / 976388$

Joyner, P. U., Thomason, T. E., \& Blalock, S. J. (2009). Practice settings, job responsibilities, and job satisfaction of nontraditional PharmD and BS pharmacy graduates. American Journal of Pharmaceutical Education, 73(2), 1-6

Ley 20129 Establece un sistema nacional de aseguramiento de la calidad de la educación superior [Establish a national system of quality assurance of higher education]., Pub. L. No. Law 20129 (2006). https:// www.leychile.cl/Navegar?idNorma $=255323$

Res. 515 Aprueba política nacional de medicamentos en la reforma de salud [Approves National Policy of Medicines in Health Reform], (2004). https://www.minsal.cl/wp-content/uploads/2015/09/ RESOLUCION_515_04_POLITICA_MEDICAMENTOS.pdf

Oliver, R.L. (1980). A Cognitive Model of the Antecedents and Consequences of Satisfaction Decisions. Journal of Marketing Research, 17(4), 460. https://doi.org/10.2307/3150499

Pace, C.R. (1979). Measuring outcomes of college: Fifty years of findings and recommendations for the future (1st ed.). Josey-Bass

Phillips, A.W., Reddy, S., \& Durning, S.J. (2016). Improving response rates and evaluating nonresponse bias in surveys: AMEE Guide No. 102. Medical Teacher, 38(3), 217-228. https://doi.org/10.3109/0142159X. 2015.1105945

Universidad Austral de Chile. (n.d.). Malla curricular Química y Farmacia, Universidad Austral de Chile [Pharmacy Curriculum, Universidad Austral de Chile]. Available from: https://www.uach.cl/dw/admision/ plandeestudio.php?car=1734

Valdivieso, V.D., \& Montero, J.L. (2010). El plan AUGE: 2005 al 2009 [The AUGE plan: 2005 to 2009]. Revista Medica de Chile, 138(8), 1040-1046. https://doi.org/10.4067/s0034-98872010000800015

Zapata, G., \& Clasing, P. (2016). El uso de criterios e indicadores de calidad en la acreditación de programas: diferencias entre agencias privadas de acreditación en Chile [The use of quality criteria and indicators in the accreditation of programs: differences between private agencies]. In Cuadernos de Investigación en Aseguramiento de la Calidad (Vol. 4). https://www.cnachile.cl/Biblioteca Documentos de Interes/ Cuaderno 4_Zapata-Digital.pdf 